\title{
Erratum to: A Quantitative Analysis of Lip Aesthetics: The Influence of Gender and Aging
}

\author{
Daniele Gibelli $^{1,2} \cdot$ Marina Codari $^{1} \cdot$ Riccardo Rosati $^{1} \cdot$ Claudia Dolci $^{1} \cdot$ Gianluca $^{2}$ \\ Martino Tartaglia ${ }^{1} \cdot$ Cristina Cattaneo $^{2} \cdot$ Chiarella Sforza $^{1}$
}

Published online: 15 August 2015

(c) Springer Science+Business Media New York and International Society of Aesthetic Plastic Surgery 2015

\section{Erratum to: Aesth Plast Surg DOI 10.1007/s00266-015-0495-7}

The metadata listing the authors' Given Names and Family Names are wrong. The correct order is given in this erratum. The authors regret their error.

The online version of the original article can be found under doi:10.1007/s00266-015-0495-7.

Daniele Gibelli

daniele.gibelli@unimi.it

1 Dipartimento di Scienze Biomediche per la Salute, Università degli Studi di Milano, Via Mangiagalli 31, 20133 Milan, Italy

2 Sezione di Medicina Legale, Dipartimento di Scienze Biomediche per la Salute, LABANOF, Laboratorio di Antropologia e Odontologia Forense, Milan, Italy 